\title{
O PROCESSO DE APRENDIZAGEM E A RELAÇÃO COM A COMUNIDADE NAS ESCOLAS DO CAMPO MULTISSERIADAS
}

\section{THE LEARNING PROCESS AND ITS RELATION WITH THE COMMUNITY IN MULTISERIATED COUNTRYSIDE SCHOOLS}

\author{
Denise Macedo Ziliotto \\ Professora do Programa de Pos Graduação em Educação da Universidade La Salle, Canoas, RS, Brasil \\ Pos Doutora pela Universidade de Lisboa, Doutora em Psicologia Social pela USP \\ denise.ziliotto@unilasalle.edu.br \\ Rita de Cassia Souza de Vargas Ferreira \\ Mestre em Educação pela Universidade La Salle, Canoas, RS, Brasil \\ rita.pufv@gmail.com
}

\section{Resumo}

Este artigo analisa as escolas multisseriadas situadas no contexto do campo, buscando identificar as singularidades desta modalidade de oferta educativa, especialmente nos processos pedagógicos e nas relações estabelecidas com a comunidade. A investigação qualitativa de cunho exploratório foi desenvolvida em cinco escolas multisseriadas da região denominada Rota das Terras (RS), a partir de entrevistas, observação participante, fotografias e documentos, analisados sob a perspectiva hermenêutica. Como resultados da pesquisa salienta-se a expressiva participação da comunidade na escola em atividades pedagógicas e administrativas, o restrito acompanhamento pedagógico aos professores pelas secretarias municipais de Educação e a prevalência da seriação neste contexto. Salienta-se a importância de estudos que proporcionem a visibilidade das escolas multisseriadas, considerando suas potencialidades e desafios enquanto proposta pedagógica, numa perspectiva não hegemônica de Educação.

Palavras-chave: Classes Multisseriadas. Comunidade. Escola do campo. Escolas Multisseriadas. Unidocência.

\begin{abstract}
This article analyzes multiseriated schools located in the countryside context, seeking to identify the singularities of this educational offer modality, especially on aspects related to the pedagogical processes and the relations they establish with the community. This qualitative research of exploratory nature was developed in five multiserial schools in the region called Rota das Terras (RS), based upon interviews, participant observation, photographs and documents, all analyzed from a hermeneutic perspective. As for the research results, we highlight the expressive community participation in the school in pedagogical and administrative activities, the strict pedagogical accompaniment to teachers by the municipal departments of Education and the serialization prevalence in this context. We emphasize the importance of studies that provide visibility for
\end{abstract}


multiseriated schools, considering their potential and challenges when treated as a pedagogical proposal, in a non-hegemonic education perspective.

Keywords: Multiseriate classes. Community. Countryside school. Multiseriate Schools. One-teaching.

\section{Introdução}

As escolas multisseriadas são oriundas do período histórico que remete ao Brasil Colônia, onde professoras leigas lecionavam para os filhos dos donos das terras e de seus trabalhadores, logo após a saída dos jesuítas do país em 1759 (CARDOSO; JACOMELI, 2010). Neste cenário, os projetos para a educação no Brasil reportavam a realidade de outros países onde primeiros educadores e escolas eram ligados à Igreja, e estavam intimamente relacionados com os interesses dos senhores escravocratas (TAFAREL; MOLINA, 2012).

Atualmente coexistem diferentes formas de organização de turmas multisseriadas no Brasil, podendo compreender a escola como um todo, constituída por uma única turma, com um único professor ou constituir classes que congregam alunos com níveis de escolaridade próximos - do $1^{\circ}$ e $2^{\circ}$ anos em uma turma; $3^{\circ}, 4^{\circ}$ e $5^{\circ}$ anos em outra turma, por exemplo - respondendo às demandas contextuais. A presente investigação pauta-se pela pesquisa em escolas multisseriadas, referida pela primeira modalidade explicitada acima.

Conforme dados do Censo da Educação Básica (2019) a rede municipal é a que apresenta a maior proporção de matrículas em escolas rurais $(19,5 \%)$, seguida da rede estadual com $5,2 \%$ das matrículas, o que repercute na capacidade de investimentos relativos à educação básica. Ao prevalecerem as escolas municipais na zona rural, também são prevalentes os índices preocupantes em relação à infraestrutura: somente 40,1\% possuem bibliotecas, 35\% laboratórios de informática, 55,9\% acesso à internet e $30 \%$ quadras de esporte, o que se distancia das escolas federais, onde estes recursos passam do percentual de $95 \%{ }^{1}$ (INEP, 2019).

De acordo com Santos e Moura (2010), a maioria das escolas multisseriadas possuem instalações em espaços geralmente com arquitetura inadequada, com iluminação

\footnotetext{
${ }^{1}$ Soma-se a este contexto o fechamento de quase 80 mil escolas do campo brasileiro entre 1997 e 2018 (ALENTEJANO; CORDEIRO, 2019).
} 
e ventilação insatisfatórias, com materiais e móveis antigos, constituída por apenas uma única sala de aula e considerada como uma escola isolada - "relegado ao descaso: quase sempre faltam livros, materiais didáticos, merenda escolar; o transporte oferecido é inconstante" (p.2). Os autores atrelam o silenciamento sobre esta realidade à resistência que o Estado brasileiro demonstra para reconhecer estas circunstâncias e dispor os recursos necessários para revertê-las. assinalam também que as universidades contribuem para esta invisibilidade, devido à escassez de pesquisas neste âmbito, não disseminando a importância e a resistência das classes multisseriadas.

Para enfrentar os desafios que a educação do campo enseja, Martins (2015) entende que é fundamental estabelecer parcerias com os entes federados para reduzir os entraves ao direito à educação de crianças, jovens e adultos do campo que pertencem a essas escolas. Salienta também a relevância e a necessidade da realização de novos estudos em nível acadêmico sobre a educação no campo, escolas multisseriadas e suas demandas.

Nesta perspectiva, desenvolveu-se pesquisa qualitativa e exploratória em escolas multisseriadas sediadas na zona rural de cinco municípios do interior do Rio Grande do Sul, tendo como instrumentos de coleta de dados documentos institucionais, entrevistas, fotografias e observação participante. A investigação centra-se nos processos pedagógicos e nas relações estabelecidas com a comunidade presentes no contexto analisado. A relevância da pesquisa considera a restrita produção científica existente sobre a temática e a importância da visibilidade das experiências neste escopo.

\section{As escolas multisseriadas: escopo e problematização}

Ao referir escolas/classes multisseriadas, primeiramente, faz-se necessário relacioná-las ao espaço do campo, pois mesmo que se apresentem em outros cenários, é esse é o território que essas escolas ou turmas existem predominantemente, constituindo o local onde se constituem na sua máxima expressão identitária (DRUZIAN; MEURER, 2013). Ao circunscrever este contexto, é importante estabelecer distinções entre a educação rural e a educação do campo.

A Educação Rural no Brasil situa-se no processo de industrialização, na década de 1930, marcada pelo discurso de modernização do campo "e da necessidade de adaptar o camponês e suas práticas, sinônimo de atraso, aos novos padrões de agricultura que 
dariam suporte ao modelo industrial nascente" (FREITAS, 2011, p.36). A Educação do Campo, por sua vez, é constituída na redemocratização do Brasil na década de 1980, fruto da articulação dos movimentos sociais do campo, que desenvolve propostas pedagógicas ensejando uma nova concepção de campo de educação e do papel da escola. Há o reconhecimento da identidade dos sujeitos sociais do campo em sua diversidade -os espaços da floresta, da pecuária, das minas, da agricultura, pescadores, caiçaras, ribeirinhos, quilombolas e extrativistas - reconfigurando-se a reivindicação de políticas educacionais, em consonância com a Resolução CNE/CEB n ${ }^{\circ}$ 1/2002 (op cit, p.40).

Nesta direção, a concepção de educação e, por consequência, de escola do campo, se contrapõe à visão tradicional de educação rural. A expressão 'do campo' designa um espaço geográfico e social que possui características próprias, sendo parte do mundo e não como algo que se opõe ao urbano. O campo é identificado enquanto "espaço social com vida, identidade cultural própria e práticas compartilhadas, socializadas por aqueles que ali vivem" (INEP, 2007. p.8)

Neste escopo, as escolas multisseriadas do campo, em sua quase totalidade, apenas um professor, o que torna unidocência e multisseriação termos equivalentes, pois reunem alunos de diferentes séries e níveis em uma mesma sala de aula. Os docentes acumulam atividades administrativas e de manutenção da unidade escolar, nem sempre contando com capacitação específica ou material pedagógico adequado, ocasionando sobrecarga de trabalho aos professores e rotatividade dos profissionais, o que possivelmente gera impactos no processo educativo (INEP, 2007).

Não há uma legislação específica que normatize essas classes, mas há dispositivos legais que, indiretamente, referem-se a esta modalidade. Na lei de Diretrizes e Bases da Educação Nacional (LDBN), é possível localizar, em seu $23^{\circ}$ artigo, a menção que educação básica pode ser ofertada de diversas formas, como:

\footnotetext{
A educação básica poderá organizar-se em séries anuais, períodos semestrais, ciclos, alternância regular de períodos de estudos, grupos não seriados, com base na idade, na competência e em outros critérios, ou por forma diversa de organização, sempre que o interesse do processo de aprendizagem assim o recomendar (BRASIL, 1996).
}

Contando com infraestrutura muitas vezes precária, as escolas multisseriadas atendem, majoritariamente, alunos dos anos iniciais do ensino fundamental. Ao receberem, simultaneamente, estudantes de diversos anos escolares agrupados numa 
mesma sala de aula, um professor é responsável por coordenar o processo (modalidade unidocente). Sendo assim, as escolas possuem uma organização diferenciada, o que demandaria formação específica para os professores. Estas especificidades constituem um desafio para os docentes que atuam junto aos alunos de idades e graus de escolaridades diferentes em um mesmo tempo e espaço (MARTINS, 2015).

Para Moraes et al (2010) as escolas do campo se estabelecem em sua maioria na forma da multisseriação e demarcam espaços heterogêneos, caracterizando-se assim, ao reunir grupos de idade, sexo, interesses, conhecimento e aproveitamento diferentes. Essas diferenças que se concretizam na multissérie, na seriação ou em qualquer outra forma de organização de ensino, se articulam às especificidades identitárias relacionadas a fatores geográficos, ambientais, produtivos, culturais, que precisam ser consideradas na formulação de políticas públicas.

A maioria das escolas multisseriadas enfrenta grandes desafios para que se configurem de acordo com os marcos legais e parâmetros definidos pelo ensino público, especialmente no que se refere à qualidade de ensino pleiteada pelas lutas dos movimentos sociais do campo. A falta e/ou a ineficiência de políticas públicas especialmente da política educacional para meio rural - envolvem fatores macro e micro estruturais, como a desigualdade e exclusão social e o fracasso escolar dos alunos. Este último aspecto se evidencia nos elevados índices de distorção idade-série, de reprovação e nas dificuldades de aprendizagem da leitura e escrita, entre outras questões que comprometem o ensino e a aprendizagem nas escolas rurais com turmas multisseriadas (HAGE, 2014).

Segundo Pereira (2010), as regiões do norte e nordeste são as regiões do Brasil que apresentam a maior situação de precariedade e pobreza, com relação à qualidade e à quantidade de recursos existentes nas escolas, especialmente nas escolas do campo. Desta forma, apresentar expectativas de um bom desempenho escolar, sem as condições mínimas de infraestrutura, equipamentos, materiais e profissionais qualificados para a educação, assistência e alimentação, torna-se impossível. Teruya et al (2013) ressaltam que, apesar das dificuldades, a oportunidade de refletir sobre a realidade de uma escola do campo enseja olhares também sobre a educação brasileira, reconhecendo potencialidades e lacunas nessa oferta educativa. 
Considerando que essa modalidade de ensino vigora há tempo considerável - seja para cumprir a lei que orienta a universalização da educação ou para possibilitar acesso à educação aos sujeitos que residem em contextos geográficos distantes dos centros urbanos - é relevante identificar elementos históricos atinentes ao objeto de estudo. A seguir são apresentados aspectos que inicidem nesta perspectiva, ampliando as matizes de compreensão da temárica.

\section{Percurso histórico das escolas multisseriadas}

As escolas ou classes multisseriadas têm sua origem no governo imperial, a partir da Lei Geral do Ensino de 1827 que definia que em todas as cidades, vilas e lugares populosos, contariam com as escolas de primeiras letras que forem necessárias (BRASIL, 1827). A partir das últimas décadas do século XIX, as escolas de primeiras letras, assim chamadas, dividiram o espaço com os grupos escolares que determinavam uma nova dinâmica escolar, de forma graduada e seriada que se encontra atualmente nos dias de hoje (CARDOSO; JACOMELI, 2010).

Concebidos como modelos para a oferta da educação, sobretudo por possibilitar melhor aproveitamento e rendimento do tempo, os grupos escolares tiveram uma história muito diferenciada nos estados brasileiros. Até então, a educação nos diversos estados (e nas diversas províncias do Império) seguia normativas constituídas pelos Departamentos de Instrução Pública para os níveis de ensino primário, profissional e normal, o que se originava da divisão entre os poderes provinciais e imperial ocorrida em 1834. Essa visão foi rompida quando as diretrizes gerais sobre a educação no Brasil, provindas de um órgão central, neste caso, o Ministério da Educação e Saúde, pretendiam unir o tempo e o espaço escolar, assim como seus conteúdos e métodos (FARIA FILHO; VIDAL, 2010).

Embora tendo se constituído grupos escolares nas vilas e povoados, as escolas multisseriadas continuavam a existir, mesmo de forma isolada e voltada atender os problemas de baixa densidade populacional. Estas escolas, unidas aos grupos escolares, denominavam-se escolas reunidas e mantinham na mesma sala entre 60 a 100 alunos, caracterizando-se pela unidocência, onde o professor utilizava o método misto (CARDOSO; JACOMELI, 2010).

As denominadas escolas rurais foram utilizadas como estratégias de contenção do fluxo migratório do campo para a cidade, mais do que como espaços formativos, 
caracterizando-se pelo atendimento de necessidades educacionais elementares e pelo treinamento de mão de obra. Nesta configuração assume um caráter discriminador, atuando para a manutenção da estrutura social e do urbanismo voltado para determinados grupos populacionais (VENDRAMINI, 2015).

Uma nova reconfiguração econômica brasileira a partir de 1990 ensejou uma reestruturação da organização administrativa educacional, num período pós ditadura militar e de adoção das políticas neoliberais. Houve a municipalização do ensino, sobretudo dos anos iniciais e no contexto do campo, em todo o país, e a partir da Lei de Diretrizes e Bases da Educação Nacional, LDB No 9394/96, houve fechamento de escolas/classes multisseriadas do campo, com a nucleação nas sedes dos municípios. Concomitantemente, houve a constituição da Educação do Campo, resultado das lutas dos movimentos sociais pelo acesso às políticas públicas de educação aos trabalhadores que produzem sua vida neste contexto (JANATA; ANHAIA, 2015).

As proposições do Estado para a escola em meio rural, em resposta à pressão dos movimentos sociais, caracterizavam-se pelo limite de verbas, pela descontinuidade e não efetividade das políticas para esta população. A lógica economicista que analisa desfavoravelmente as escolas pequenas e com poucos alunos, investe em ações como o tele-ensino, a formação dos professores à distância, oferta de ensino com intuito de instrumentalização dos jovens e uma concepção de ensino regido pela lógica empresarial (VENDRAMINI, 2015).

Para Molina e Freitas (2011) é possível identificar, na maioria das unidades federativas, experiências com diferenciados graus de protagonismo dos movimentos sociais relativo às escolas rurais dos sistemas municipais e estaduais, oriundas do Movimento da Educação do Campo. Contudo há muitos desafios apesar dos avanços obtidos pelos marcos legais e políticas públicas, pois ocorre um grave processo de fechamento das escolas rurais, ao mesmo tempo que se produzem possibilidades e legitimidade destas, mas também se reduz a cada dia o número de escolas no campo.

Sobrepõe-se a este cenário o advento na nucleação, que não foi balizado proporcionalmente pela redução das matrículas dos estudantes no contexto das escolas do campo. Em 1997 havia cerca de 7,4 milhões de alunos em escolas rurais, e em 2018 compreendiam em torno de 5,4 milhões, configurando uma redução de 26,1\%, ante ao fechamento de $58 \%$ de escolas no mesmo período. Dentre as consequências desta política 
está o tempo maior de deslocamento e a possibilidade de evasão dos estudantes diante das dificuldades vivenciadas (ALENTEJANO; CORDEIRO, 2019).

Evidencia-se em diferentes momentos históricos a extensão de políticas educacionais ao contexto do campo, sem observar sua especificidades ou mesmo remetendo-o a desempenhar condições estabelecidas de formação que se distinguem de outros contextos, como analisado a seguir.

\section{Escola do campo a partir do paradigma da escola urbana}

No entender de Hage (2005), as escolas multisseriadas precisam ter mais visibilidade e ser incluídas na agenda das Secretarias Estaduais e Municipais de Educação, do Ministério da Educação, das universidades e centros de pesquisa, e dos movimentos sociais do campo. A pesquisadora defende a necessidade deste reconhecimento - inclusive nos dados estatísticos do censo escolar oficial - desfazendo a negligência do poder público e da sociedade. A desconsideração por parte da sociedade e do Estado remete às essas escolas situações precárias nas comunidades onde se localizam, sendo que muitas vezes se constitui na única possibilidade de iniciação escolar de crianças e adolescentes da área rural.

A escola cumpre uma importante função de reconhecer e disseminar as culturas, os modos de vida, os saberes e as identidades locais. Para Duarte e Taschetto (2014, p.36), a defesa da não nucleação das escolas vincula-se à defesa desta perspectiva, e ainda: "É no espaço escolar que, não raro, se organizam coletivamente os sujeitos da comunidade para ali discutirem diferentes questões que lhes dizem respeito, inclusive questões que apontam/denunciam a minimização do Estado nesses locais".

Segundo Hage (2014) as especificidades e condições vivenciadas pelas escolas multisseriadas contribuem para uma visão desqualificada da escola da área rural, amparando a justificativa de sua existência como única opção para ensino dos anos iniciais nas comunidades rurais, mesmo que a responsabilizando pelo fracasso escolar dos sujeitos do campo. Nesta direção, o equacionamento da situação passaria pela transformação das escolas seriadas, adotando o modelo do meio urbano. $\mathrm{O}$ autor entende que a melhoria da qualidade das escolas rurais passa pelo enfrentarmos as dificuldades e os desafios que envolvem as condições de existência dessas escolas. Serão necessárias várias ações de forma conjunta e articulada entre o macro e o micro, entre as questões de 
estrutura e de concepção, políticas educacionais, organização do ensino e formação dos docentes e profissionais que estão presentes nessas escolas.

Conforme Moraes et al (2010) a visão de que a escola seriada urbana é referência em educação de qualidade é pautada pelo discurso generalizado que apresenta o espaço urbano como um lugar desenvolvido, moderno, com acesso à tecnologia, educação e saúde, em oposição ao meio rural. Desta forma, a reprodução da seriação nas escolas multisseriadas seria entendida como meio superar o fracasso dos estudantes nessas escolas. Para Duarte e Taschetto (2014), a invisibilidade das escolas/classes rurais, especialmente aquelas organizadas na multisseriação, é uma representação social que a coloca em um nível inferior em comparação às escolas seriadas urbanas. Por outro lado, existe movimentos que inviabilizam o seu fechamento, especialmente fundamentados na legislação por meio de decretos, pareceres e resoluções.

Parente (2104) argumenta que a multisseriação, na maioria dos casos, não atua pedagogicamente, e sim administrativa e financeiramente, a começar pela lógica na organização das multisséries, considerando apenas a necessidade de estabelecer grupo que congregue de alunos de diferentes idades/séries. Segundo a autora, a compreensão de que toda turma, por possuir sujeitos diferentes, é diferente, é central e independe da modalidade de oferta de ensino. Neste sentido, a multisseriação precisa ser analisada no âmbito de uma política educacional do sistema como um todo, em diálogo com toda a sociedade, considerando os elementos essenciais à organização dos tempos e espaços educativos.

Nesse sentido, Duarte e Taschetto (2014) defendem uma perspectiva políticopedagógica contrária às tradicionais práticas realizadas em muitas escolas multisseriadas, pautadas ainda pela lógica de seriação, que reforçam a ideia de unir várias séries em uma única turma com o professor desenvolvendo seu trabalho pedagógico ainda segmentado. Conforme Parente (2014), muitas vezes, não há critérios para a organização das turmas/classes multisseriadas para além do modelo seriado. Os norteadores políticoadministrativos ainda estão centrados na lógica da seriação e restringem as possibilidades pedagógicas a serem desenvolvidas pelos sistemas de ensino e pelos próprios docentes.

A partir da identificação dos impasses e desafios presentes para a instauração da educação no e para o campo, diante da prevalência de paradigmas do contexto urbano, foi desenvolvido o itinerário investigativo explicitado a seguir. 


\section{Percurso investigativo}

Considerando a relevância das especificidades e potencialidades das escolas dos campo multisseriadas, e com intuito de dar visibilidade e problematizar estes aspectos, realizou-se investigação deste contexto, caracterizando-se como uma pesquisa empírica de natureza qualitativa e exploratória, em função da natureza dos dados a serem investigados e da produção científica relativa ao objeto de estudo. Gil (2012) afirma que a pesquisa exploratória tem como objetivo esclarecer e desenvolver ideias, que servem para futuras pesquisas formulando e encontrando novos problemas. Complementando, Marconi e Lakatos (2009) concebem que a pesquisa exploratória tem três finalidades: gerar hipóteses, conhecer mais sobre o assunto pesquisado e também atualizar conceitos.

O lócus da pesquisa - municípios localizados no planalto gaúcho - foi estabelecido em função do acesso e possibilidades de deslocamento para as pesquisadoras. Após a apresentação do projeto de pesquisa aos responsáveis pelas secretarias municipais de educação, realizou-se uma visita às escolas para contato e convite aos professores participantes, que seriam posteriormente entrevistados. Para a escolha das escolas, priorizou-se a representação por município da região identificada, sendo que ao identificar a presença de mais de uma na cidade, levou-se em conta o critério da distância entre a sede e a escola, o número de alunos e o número de professores, elegendo-se aquela que compusesse as condições mais representativas de instituição rural.

Como fonte para a coleta de dados foram utilizados documentos institucionais, registros fotográficos, observações e entrevistas com os profissionais atuantes nas escolas. As entrevistas foram gravadas em áudio e posteriormente transcritas, sendo autorizadas previamente pelos participantes a partir do termo de consentimento livre e esclarecido. Segundo Gil (2012), a entrevista possibilita ao investigador obter dados que são importantes através da formulação de perguntas, favorecendo um diálogo entre o pesquisador e o entrevistado, obtendo informações importantes e com profundidade. Para presevar o anonimato assegurado aos participantes, não são identificados na apresentação dos dados, bem como as escolas e os municípios em que se inserem, possibilitando o compartilhamento de diversos elementos presentes no contex to analisado

Para ampliar o repertório dos dados da pesquisa também foram considerados elementos da observação realizada durante os contatos nas escolas, registrados no diário de campo. Segundo Marconi e Lakatos (2009), a observação consiste na utilização dos 
sentidos para obter certos fatos sobre o que está sendo estudado e Gil (2012) enfatiza que esta modalidade de coleta de dados também ajuda a perceber dados que não aparecem no momento da entrevista.O registro iconográfico, a partir de fotografias digitais, buscou demonstrar as informações sobre a infraestrutura da escola, a organização do espaço pedagógico e administrativo, a localização das instalações em relação ao território em que está inserida, a dimensão da ocupação por alunos e professores da escola.

A pesquisa documental foi realizada a partir de cópias fornecidas pelas Secretarias Municipais de Educação e pelas escolas, de registros e procedimentos administrativos que são atinentes ao funcionamento da unidade de ensino, bem como do projeto político pedagógico e atas, que evidenciaram a relação da escola com outras instâncias do município ou da comunidade. Gil (2012) indica que na pesquisa documental são encontrados dados importantes sobre o tema investigado através de documentos jurídicos e escolares.

A análise dos dados foi realizada dentro da perspectiva hermenêutica, que refuta a neutralidade do pesquisador, pois "trata-se de um olhar que não apenas vê, mas se vê" (ROHDEN, 2008, p. 51). O caminho da investigação com enfoque hermenêutico, considera a maneira que o pesquisador ou leitor possui diante dos textos (STEIN, 2004). Foi estabelecida a partir de um processo dialógico através da sistemática de trocas e releituras realizadas durante essa investigação, no contexto da escola, no grupo de pesquisa, nas reescritas a partir da leitura de terceiros, no distanciamento e na aproximação constante do pesquisador do contexto analisado. Para Hermann (2003), o diálogo trata-se de uma condição adequada da hermenêutica, caracterizada pelo não domínio do sujeito em relação à subjetividade do conhecimento, anterior a isso a experiência do conhecer que advém do diálogo, oportunizando a conversação antes mesmo de se chegar ao conhecimento. Desta forma se torna claro o processo entre aprender, compreender e dialogar.

\section{Apresentação e discussão dos resultados}

O lócus da pesquisa - a região conhecida como Rota das Terras Encantadas constitui-se em conjunto de municípios que se propõe ao desenvolvimento turístico e ambiental, denominado, oficialmente, Conselho de Desenvolvimento Sustentável da 
Região Planalto/Consórcio Rota das Terras (CONDESUS/Rota das Terras.Segundo a Secretaria do Turismo do Estado (2018), 16 municípios compõem a a região situada no Planalto Gaúcho, mais precisamente no Planalto Médio do Rio Grande do Sul, como abaixo identificados:

Figura 1 - Localização dos municípios

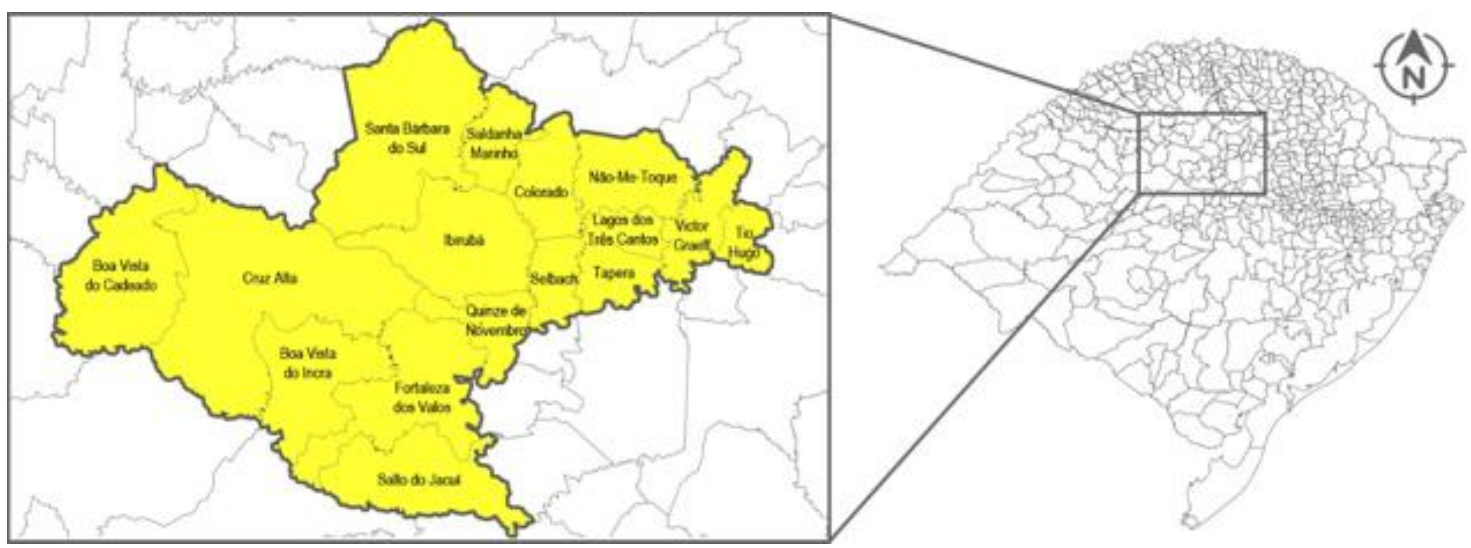

Fonte: Base de dados cartográficos (IBGE, 2010).

Dentre eles foram selecionadas cinco municípios e respectivamente cinco escolas para participarem da investigação, tendo como critérios de inclusão a presença de escola multisseriada, o consentimento com a participação e, por conveniência, a proximidade de deslocamento entre os municípios.

Tabela 1 - Características das escolas pesquisadas

\begin{tabular}{lllll}
\hline Escola & Prof & Alunos & Func. & Participante \\
\hline A & 1 & 28 & 3 & Professor A \\
B & 2 & 13 & 3 & $\begin{array}{l}\text { Professora B } \\
\text { Professora B1 } \\
\end{array}$ \\
& & & & Professora B2 \\
C & 1 & 22 & 2 & Professora C \\
D & 3 & 23 & 4 & Professora D \\
E & 1 & 8 & 2 & Professora E \\
\hline \multicolumn{5}{l}{}
\end{tabular}

Os dados coletados na pesquisa foram analisados a partir de duas dimensões pedagógica e comunitária - estabelecidas como aspectos enfatizados pelos participantes e emergentes diante da coleta de dados. 
Dimensão pedagógica das escolas pesquisadas

Nas escolas A e B os professores moram na comunidade e nas escolas C, D e E, os educadores são provenientes de outras localidades ou municípios. A inserção e o conhecimento da realidade da escola e da comunidade repercutem na prática pedagógica, pois esta presença favorece o conhecimento dos alunos e do contexto de vida das famílias. Este aspecto é evidenciado no depoimento do professor A:

Já tive propostas boas para sair, escolas particulares e universidades. Mas não sei se teria essa capacidade, porque gosto mesmo é de colocar a mão na massa. Sou uma pessoa do campo e gosto de trabalhar na terra. E trabalhamos na terra com as crianças, plantamos. É lá no mato que vamos pegar uma folha de árvore para estudar. (Professor A).

Para Azevedo e Queiroz (2010), o vínculo do professor ao meio em que trabalha é fundamental para a construção de uma identidade de atuação, pois o entendimento da cultura e da situação enfrentada por aquela comunidade é decisiva. O pertencimento do professor possibilita reconhecer as dimensões cultural e político-pedagógica, consequentemente gerando maior envolvimento na aprendizagem.

Figura 2 - Escola C: Layout Sala de Aula

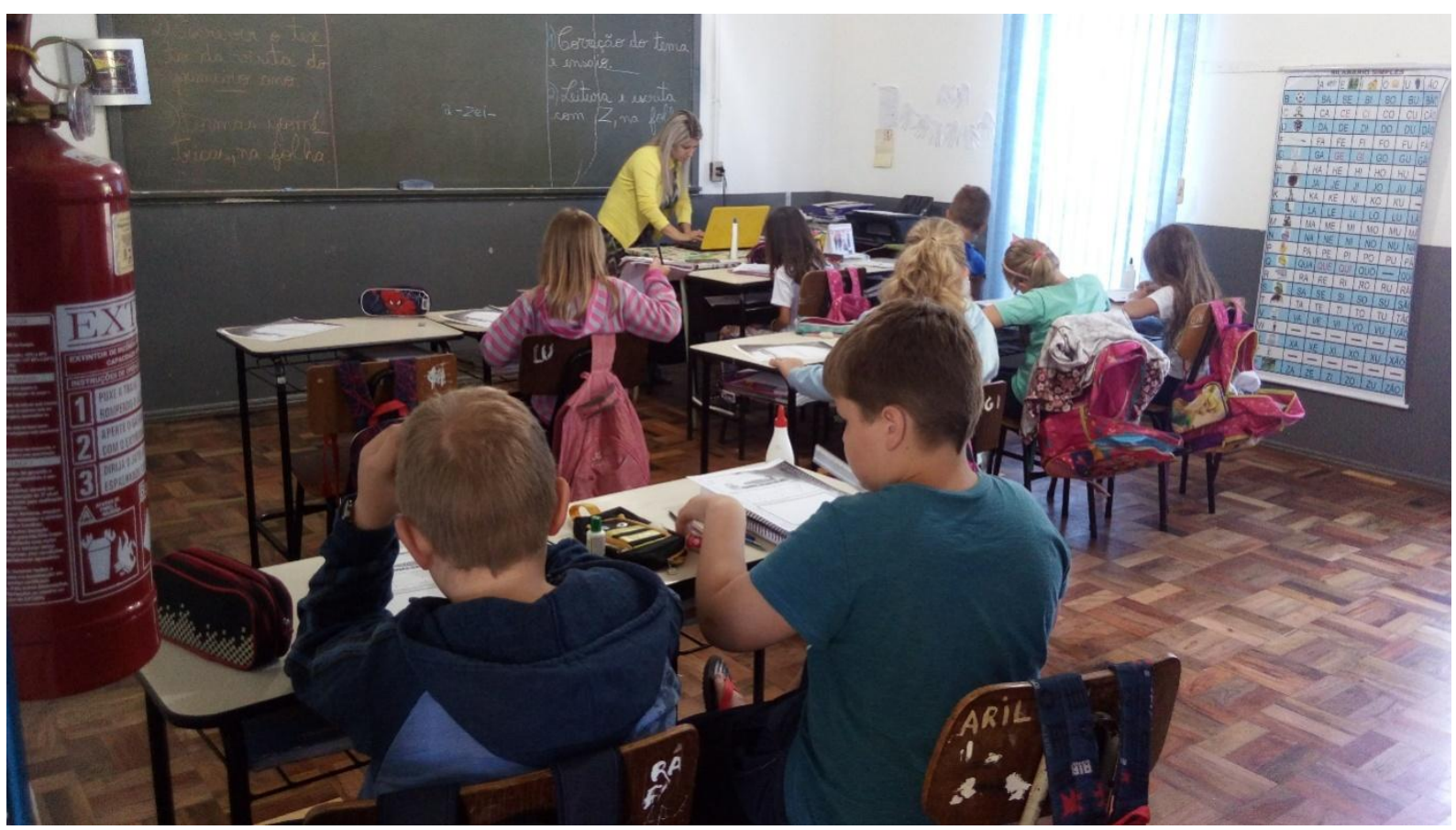

Fonte: Acervo pessoal das pesquisadoras, 2018. 
Um desafio significativo, em relação à dimensão pedagógica, é a existência de um modelo seriado ainda contemplado pelos professores em escolas/turmas multisseriadas. $\mathrm{Na}$ escola $\mathrm{C}$, conforme identifica a figura a seguir, a organização do espaço escolar ainda se pauta pelo modelo seriado explicitado no uso do quadro negro e a distribuição das crianças por turma.

A professora $\mathrm{C}$ descreve esta organização pedagógica existente em sua escola:

Por mais que tu tenhas hora atividade, não dá tempo, porque tu tens quatro turmas para planejar... que nem eu digo: eles são calmos, melhor coisa que tem é dar aula no interior. Dar aula é o de menos, só que tipo, eu não sento a manhã inteira. Tu não para, porque são quatro aulas diferentes, tu tens que estar atendendo todo o tempo (Professora C).

Em relação às estratégias de ensino aprendizagem, nas escolas B, D e E, os professores também demostram a ansiedade por vencerem os conteúdos, e planejam, majoritariamente, considerando a separação dos conteúdos por turma. Foi possível observar que a divisão do quadro, o planejamento por turma e o agrupamento de séries fazem parte da dinâmica dessas escolas:

Quando eu iniciei, tive que me desafiar e buscar muito, então eu aprendi a pesquisar para fazer esse planejamento diferenciado. O primeiro ano foi bem exaustivo porque eu não estava acostumada com isso: ter que atender um aqui, outro chama ali, até dividir o quadro para poder escrever. Às vezes uma folhinha para um e depois escrever no quadro para outro (Professora E).

A professora B2, que atende uma turma multisseriada na fase de alfabetização argumenta sobre a dificuldade de trabalhar com séries diversificadas quanto aos conteúdos e interesses, especialmente em razão do processo inicial da etapa escolar. Na turma com crianças de pré-escola e $1^{\circ}$ ano, conforme a professora, falta a concentração dos maiores devido à dispersão dos alunos menores:

A minha maior dificuldade, é conseguir trabalhar com as duas turmas.Na préescola iniciamos o letramento e o primeiro ano está aprendendo a ler e a escrever sozinho. O pré tem a necessidade mais de brincar, é difícil estar todo o tempo interagindo com eles, que seria bem importante. [...] são faixas etárias diferentes, eles são menores. O primeiro ano já não entende porque que o pré tem menos atividades, mais fáceis e assim às vezes o contrário também. Fica difícil esse entendimento, tem que estar todo o tempo retomando (Professora B2). 
$\mathrm{Na}$ escola $\mathrm{D}$, as professoras realizam a articulação entre as turmas de forma seriada, dividindo as séries por grupos, onde os alunos com maior dificuldade ou que necessitam de um olhar mais especifico, ficam mais próximos à professora, segundo a gestora da escola:

Elas (referindo-se às professoras) tentam mesclar: fazem um texto e de acordo com o nível que o aluno está, elas fazem as atividades... a professora D1, com a turma maior, que são três. Ela faz três mesinhas, uma para o pré-1, uma para o pré-2 e os alunos do primeiro ano, que precisam de um atendimento mais de perto. Ela coloca eles ao redor da mesa dela. E aqui com o terceiro ano também, os alunos inclusive que tem mais dificuldades ficam mais perto da professora. É uma maneira que elas encontram para conseguir atender. (Gestora, Escola D).

Os principais desafios enfrentados pelos professores são a organização e planejamento pedagógico que considerem o tempo e o espaço da diversidade que as turmas multisseriadas comportam. Os professores das escolas A e E entendem que o planejamento deve ser diversificado e atraente para contemplar todos os alunos:

Quando tu trabalhas com projetos, tu te desafias mais, tu propões coisas diferentes, tu envolves o aluno, o aluno é protagonista. Então acho, que o projeto é fundamental, dá cor, dá cheiro, dá sabor para as nossas aulas (Professora E).

Buscamos trabalhar dentro da nossa pedagogia da escola. A gente valoriza muito a questão ambiental, a produção de forma sustentável e alimentação saudável. A gente trabalha na escola e procura fazer como um laboratório que depois se estende as famílias[...] A criança precisa ser desafiada, e no momento que ela vencer o obstáculo, cria-se outro para ela. E dentro da escola multisseriada, quando uma criança - por exemplo, ela já sabe tudo que ela poderia aprender dentro do currículo dela - eu já vou dando minhas estocadinhas para frente (Professor A).

Outro aspecto identificado a partir da análise dos Projetos Políticos Pedagógicos (PPP) das escolas, entrevistas e diário de campo, trata-se da perspectiva homogeneizadora da compreensão de currículo que sobrevaloriza uma concepção urbanocêntrica de vida e de desenvolvimento, e não considera em sua essência, as experiências e vivências do campo em toda a sua diversidade cultural. Este aspecto fica evidente nos depoimentos a seguir:

Nas reuniões de estudo a gente até teve dificuldade por conta que a nossa realidade é diferente das outras escolas, mas a gente participa igual das reuniões de estudo para não ficar de fora. Porque são realidades diferentes. [...] é utilizado esse tempo como planejamento. Daí, de certa forma tem aplicabilidade, mas assim: uma pessoa superior a nós, que fica dando um 
suporte assim - a gente não teria nessa noite no caso - como nas outras escolas, que tem as supervisoras (Professora E).

Essa parte do apoio pedagógico poderia ser mais, a presença na escola, isso falta. Elas não têm tempo para vir na escola. Nesse sentido a gente se sente abandonada. Que nem as escolas maiores, que têm a parte pedagógica, a coordenação, que querendo ou não é um apoio. A gente não tem, isso que falta, digamos é eu para tudo (Professora C).

[...] nesse sentido poderia ter um apoio mais direto, porque a gente sabe, eu convivo com os colegas e a gente vê que nas outras escolas a professora tem tempo de fazer tudo, pois tem uma coordenadora pedagógica dentro da escola, que ajuda a organizar e um secretário. Aqui é tudo nas minhas mãos, tenho que fazer tudo, e além disso tenho que conseguir que as minhas crianças sejam bem alfabetizadas, sejam bem atendidas. (Professor A).

Neste contexto, a formação continuada dos professores e acompanhamento pedagógico que contemple as singularidades do modelo multisseriado não se efetiva. No relato dos professores, o acompanhamento pedagógico por parte das Secretarias Municipais de Educação remete a um modelo seriado, onde a participação e planejamento entre os professores ocorrem com outras escolas, que na maioria das vezes, se torna inviável para o professor da multisseriada, por não contemplar a troca entre pares. A partir das indicações dos participantes percebe-se a importância da construção de uma proposta educativa para a escola do meio rural organizada sob a forma da multisseriação.

Nas escolas pesquisadas observou-se a participação ativa das crianças no processo ensino-aprendizagem, característica presente na visita realizada na escola A, onde as crianças brincavam na areia e ao mesmo tempo aprendiam as frações. Em outra situação, as pesquisas relacionadas ao projeto que os alunos estavam estudando eram realizadas em um pequeno microscópio que havia na sala - equipamento adquirido através da mobilização da comunidade - enquanto o professor dialogava sobre o projeto, as crianças criavam suas perguntas, resolviam e aprendiam juntas.

$\mathrm{Na}$ escola, o estudante deveria aprender a partir das relações que estabelece com seu contexto de vida, com as interações que realiza juntos aos pares, gerando e resolvendo os conflitos diários apresentados. Neste sentido o professor torna-se um mediador durante as atividades desenvolvidas, os alunos participam ativamente de sua aprendizagem e o sentido de ensinar e aprender se torna mais significativo. Observa-se no contexto das escolas pesquisadas - a partir das diferentes fontes de coleta de dados - um movimento dinâmico e inovador nas práticas pedagógicas, proporcionando o espaço para que os estudantes possam tornar-se mais ativos durante as atividades propostas, outro aspecto 
comum a estas escolas no que se refere às práticas pedagógicas e o trabalho com projetos de aprendizagem, no qual o aluno é protagonista e também pode decidir sobre o que estudar.

A exploração dos espaços e materiais pedagógicos existentes fazem parte do processo de aprendizagem dos estudantes, que inseridos no contexto da sala de aula, possibilitam o acesso diário dos alunos aos recursos existentes na escola. O professor $\mathrm{A}$ informa a utilização do espaço da leitura construído dentro da sala de aula, como uma possibilidade de garantir o gosto pelos livros, além da autonomia e protagonismo das crianças em ter o acesso dentro da própria sala:

\begin{abstract}
A gente prioriza muito a questão da leitura. Essas crianças pequeninhas entram na escola com quatro aninhos e o primeiro dia de aula eles já saem daqui com um livrinho para casa. Claro que eles não leem, mas eles olham. A pai e a mãe leem. Na segunda-feira e na sexta-feira são os dias de devolver o que levou e escolher um novo. São os dois dias que o eu entrego a atividade para eles. No computador tem a ficha de leitura, eu chamo a criança e eles seguem trabalhando e vou chamando. [...] então você vai no baú de literatura, pega o teu livrinho novo, volta, a gente registra. A gente faz isso na segunda e na sexta com os pequeninhos. Terceiro, quarto e quinto ano eles mesmos fazem, eles solicitam as fichas, eles anotam, eles devolvem. (Professor A)
\end{abstract}

Figura 3 - Baús de livros Sala de Aula escola A

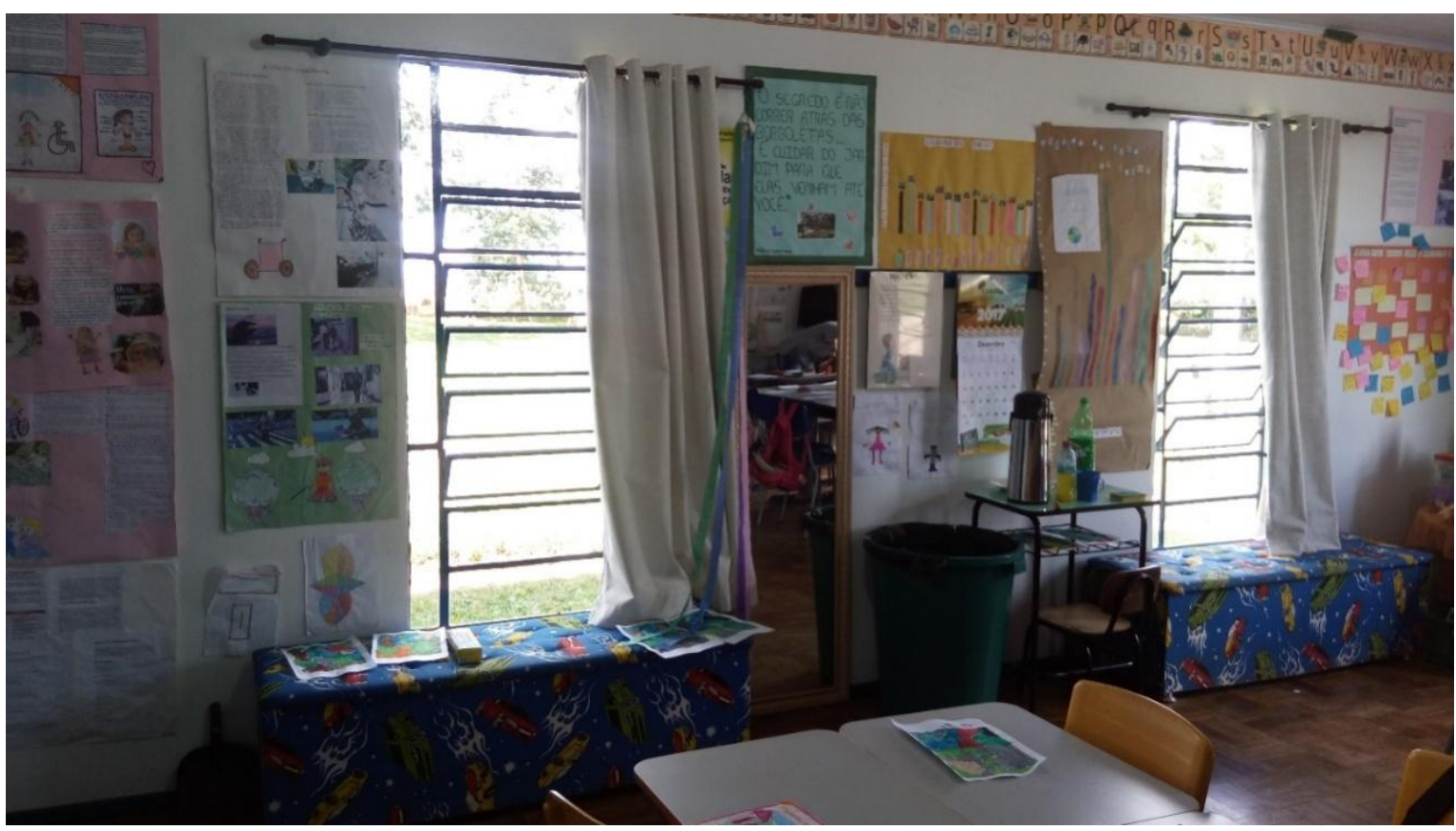

Fonte: Acervo pessoal das pesquisadoras, 2018. 
$\mathrm{Na}$ escola $\mathrm{E}$ o espaço da sala de aula é restrito em tamanho, mas com recursos disponíveis que complementam as atividades diárias dos alunos. Com uma pequena biblioteca, recursos materiais e um espaço para vídeo com tapete e almofadas as crianças constroem seus aprendizados, explorando os materiais na medida em que pesquisam determinados assuntos, facilitando a abordagem da professora.

Enquanto potencialidade do modelo multisseriado, os professores demonstraram valorizar a aprendizagem dos alunos, mesmo diante dos desafios para a organização das atividades pedagógicas. A professora B1 argumenta a importância da aprendizagem neste contexto multisseriado, onde os alunos aprendem e ensinam uns aos outros, onde os pequenos observam e geram suas expectativas em relação aos alunos maiores. Os participantes B1 e A afirmam que nas turmas existe cooperação e organização da dinâmica da sala por parte dos estudantes:

\footnotetext{
Neste ano eu estou trabalhando com o segundo e quinto ano. Muitas vezes você explica para o aluno e ele não consegue entender; com a explicação de um colega muitas vezes, com uma linguagem mais próxima, eles conseguem entender melhor. E a minha turma, ela se ajuda muito, ela é participativa e organizada. Então eles mesmos se organizam também na sala de aula (Professora B1).

Pedagogicamente o modelo de escola multisseriada, tem mais vantagens que desvantagens. Eu digo porque a gente dentro da sala de aula - se planeja uma atividade motivadora, que engloba tuas turmas - eles iniciam o trabalho e aí as crianças que sabem mais, elas repartem com os que sabem menos. Há uma troca muito maior de conhecimento e envolvimento (Professor A).
}

Sem dúvida, o modelo multisseriado apresenta seus desafios, mas sobretudo, suas potencialidades que evidenciam uma aprendizagem mais significativa. Corroborando com esta afirmação, Arroyo (1999) destaca que a escola seriada é umas das instituições que mais seleciona e exclui dentro da sociedade brasileira, reforçando que a escola não pode acontecer dentro de quatro paredes, apenas nos espaços de uma sala de aula, repensar os tempos e os espaços escolares que atendam as demandas da educação do campo.

\section{Dimensão Interface Comunitária}

As escolas pesquisadas apresentam uma relação próxima com a comunidade, evidenciada na participação ativa na escola, não somente em eventos, mas também na 
participação da gestão escolar. Identifica-se a mobilização da comunidade para a busca de recursos financeiros, materiais e humanos que apoiem a existência da escola, como a aquisição do microscópio na escola A e na realização das atividades de manutenção, através de mutirões para a limpeza na escola E.

A participação da família na escola é reconhecida pelo professor A: "Eles têm uma participação muito grande, é a isso que eu atrelo a gente ter um bom desempenho pedagógico dentro da sala de aula. Porque as famílias, desde o momento em que a gente faz essas promoções para comprar determinadas coisas, elas estão junto". Conforme a professora $\mathrm{C}$, a participação ativa da comunidade dentro da escola é a principal razão para que a mesma ainda permaneça aberta. Com um número restrito de alunos, devido à migração das famílias para os centros urbanos, a permanência da escola é garantida pelos esforços somados da comunidade: "Acredito que é isso que mantém a escola ainda aberta. A escola vai fazer 100 anos e se não fosse a comunidade ser unida, a escola não funcionava mais".

A professora B1 enfatiza o caráter de resistência da comunidade, quando se refere à luta que as famílias enfrentam para manter a escola em funcionamento. "Os pais têm tido uma grave luta para que se mantenha a escola. Inclusive, esses dias, alguns pais se organizaram e não deixaram o primeiro ano ir para a cidade, pois queriam transferir para a escola do centro" (Professora B1). A professora E reconhece a participação da comunidade na escola, oriunda da compreensão de sua importância como referência e espaço de aprendizado para todos: "Eles valorizam muito o trabalho que é realizado aqui e eles têm a cultura do estudo, isso faz toda a diferença no nosso trabalho". Dentre as atividades em que a comunidade participa estão a apresentação de projetos pedagógicos, palestras educacionais, culminância dos projetos e festividades, como o dia das mães, festa junina, dia dos pais, a data de aniversário da escola e o Natal.

O PPP da escola E reforça a participação da comunidade nas atividades da escola como reconhecimento e valorização do espaço escolar:

Realizar um trabalho de parceria junto à Escola, contribuindo de forma construtiva na vivência dos princípios que norteiam o Projeto de Educação e Desenvolvimento do Município e Proposta Político-Pedagógica da Escola. Participar das atividades da escola valorizando-a como promotora da aprendizagem e da busca do conhecimento. Assumir ações integradas que visem mudanças de atitudes frente à valorização do ser humano e qualidade de vida, bem como a preservação do meio ambiente. (PPP, Escola E, 2010). 
Para a professora $\mathrm{B}$, a participação da comunidade se concentra nas festividades e eventos que a escola proporciona. Mas o PPP da escola menciona um espectro mais ampliado, ao referir que "No Ensino fundamental e Educação Infantil a metodologia adotada leva em conta a dinâmica de ensinar/aprender, como uma ação compartilhada entre professor, aluno e comunidade, incluindo sempre que possível a metodologia de projetos" (PPP, Escola B, 2012).

Observa-se a participação da comunidade nas escolas pesquisadas nos projetos desenvolvidos pelos professores e alunos, em situações como contação de histórias, rodas de conversa ou até mesmo a visita dos alunos espaços residenciais ou comerciais. A professora D dimensiona esta relação:

Quando tem eventos que precisa pedir prêmio para ajudar, organizam tudo. A gente tem muita a ajuda deles, se não fossem eles, seria bem mais difícil. [...] se a gente precisar chamar para pintar um muro, cortar uma grama, tudo, eles vêm ajudar, de super bom agrado. Sempre eles ajudam a gente, "se nós não fizermos pelos nossos filhos nós vamos fazer por quem” (famílias se referindo à escola), então eles geralmente abraçam a causa.

Outro fator importante observado refere-se à participação da comunidade na tomada de decisões em relação à escola. Por exemplo, acerca das prioridades relacionadas ao recurso financeiro gerido pelo CPM, quando os professores detalham as necessidades de materiais para o aprendizado dos alunos, solicitando à comunidade que apoie a atividade. Este fato é reforçado no projeto político pedagógico da escola D:

A escola caracteriza-se por uma prática de gestão participativa, buscando envolver a comunidade na tomada de decisões, com reuniões por turma, de pais, do CPM, Conselho Escolar, na entrega de pareceres, bem como na definição do uso de recursos financeiros. (PPP, Escola D, 2016, p.7).

O professor A salienta que o aprendizado das crianças está alicerçado em uma base sólida constituída por todos. Observa-se que o professor não vincula o ensinar/aprender somente ao contexto de sala de aula, mas há um contexto mais amplo que considera todos os espaços vivenciados pelos alunos:

Há uma procura por nossa escola, uma procura pelo conjunto da obra, não somente o professor, mas um conjunto da obra das famílias, das pessoas que trabalham. As duas pessoas que me ajudam aqui, os motoristas, a gente tem uma conversa seguida para fazer um trabalho bem feito. As famílias ajudam, é um conjunto da obra que lá no final a gente tem crianças felizes, e com crianças felizes temos crianças que aprendem. 
O contexto apresentado pelo professor é referido por Janata e Anhaia (2014) ao afirmarem que o envolvimento da comunidade favorece uma leitura mais integrada da realidade e possibilita o comprometimento coletivo, aproximando a vida da escola à vida da comunidade. Assim, o conhecimento gerado pela escola obtém relevância social e a escola passa também a ter mais sentido para todos os envolvidos.

No documento norteador da escola A, é possível perceber a importância da comunidade escolar no contexto de vida da escola, nos vínculos estabelecidos ao longo das aprendizagens e a participação desta nas atividades propostas:

\begin{abstract}
Há um vínculo social e afetivo entre a família e a escola, o que possibilita uma integração entre os participantes da comunidade escolar, o respeito e a valorização da educação junto à comunidade. Observa-se que os profissionais envolvidos no trabalho, desde o professor até a equipe multidisciplinar, também estão comprometidos e atuantes, de forma a buscar a aprendizagem e crescimento dos alunos (PPP, Escola A, 2016).
\end{abstract}

Portanto, identifica-se que a participação da comunidade é demarcada pelos movimentos em prol das escolas, na busca por recursos e infraestrutura, no impedimento da nucleação dessas turmas e na participação como comunidade de aprendizagem nos projetos desenvolvidos pelos professores e alunos. Outro fator presente na relação entre escola e comunidade se deve ao contexto inverso, de reciprocidade, onde a escola se mobilizou em prol da comunidade. O professor A indica dois momentos que demonstram o vínculo estabelecido com as famílias:

\begin{abstract}
Nós tínhamos uma dificuldade muito grande, não havia água na escola. A gente partiu a campo como professor, eu tinha que ser um gestor, tinha que trazer água para escola com bombona, de kombi. Unimos a comunidade e elaboramos um projeto, encaminhamos para a prefeitura e conseguimos água. Tivemos também na comunidade - mas foi a escola que fez isso, a gente começou - a questão do lixo. Tínhamos um problema muito sério aqui de lixo esparramado, tanto na beira da estrada, quanto nas propriedades. Criamos aqui na escola um projeto, buscamos na prefeitura a viabilidade do caminhão vir recolher o lixo, e dentro deste trabalho envolvemos a família dos estudantes, as famílias de quem não eram os estudantes. Saímos para fazer a coleta de lixo nas ruas e conscientizamos os pais para depositar o lixo na escola.
\end{abstract}

Para Santos e Albuquerque (2014), convidar a comunidade a vivenciar as atividades propostas pela escola no seu dia-a-dia, solicitando a todos para participarem ativamente nas decisões da escola e resgatar a história da comunidade, é concretizar o 
princípio da gestão democrática enfatizando a importância do contexto em que o aluno está inserido no planejamento e na prática pedagógica.

A interface da comunidade, a partir dos aspectos evidenciados, mostra-se efetiva e potencializadora da função educativa, construindo mediações pedagógicas e de gestão. Esta dimensão contribui, sobretudo, para a manutenção das escolas em atividade, atuando como resistência. A ampliação da oferta de vagas para os anos finais do ensino fundamental e para o ensino médio constituem outras frentes do pleito da

\section{Considerações finais}

Este artigo analisou as escolas multisseriadas situadas no contexto do campo, buscando identificar as singularidades desta modalidade de oferta educativa, especialmente nos processos pedagógicos e nas relações estabelecidas com a comunidade. A pesquisa qualitativa de característica exploratória foi desenvolvida a partir de investigação empírica em escolas sediadas na Região Rota das Terras (RS), tendo como instrumentos para a coleta de dados as entrevistas com professores, os documentos da escola, fotografias e observação participante, sendo analisados na perspectiva hermenêutica.

Nas escolas pesquisadas, em relação à dimensão pedagógica, o modelo multisseriado ainda é experienciado de forma restrita, como é possível verificar no planejamento das aulas, na divisão do quadro, na organização dos conteúdos por série, na disposição dos alunos na sala, sendo também presente na ansiedade dos professores pela dinâmica da turma heterogênea, aspectos que indicam a referência seriada na proposta educativa. O acompanhamento e orientação pedagógicos não são sistemáticos e efetivos pela Secretaria Municipal de Educação, possivelmente refletindo sobre os processos de ensino-aprendizagem dos alunos, não havendo uma política de formação em nenhum dos municípios pesquisados voltado ao contexto de um currículo que atenda uma turma multisseriada, heterogênea, que observe as particularidades das escolas do campo. Observou-se que os professores pesquisados atuam buscando identificar as potencialidades de cada aluno e evidenciam as aprendizagens significativas a partir das trocas entre estudantes de diferentes idades.

A comunidade partilha da escola e defende sua existência, pois as relações estabelecidas com as famílias sustentam a continuidade dessas escolas nas zonas rurais. 
Mesmo havendo um decréscimo dos alunos nestas escolas a cada ano, a família permanece mobilziada para manter a escola como um espaço de aprendizagem, configurando-a como ponto de encontro para atividades e festividades ao longo do ano. A investigação também evidenciou que as famílias participam significativamente durante a realização dos projetos de aprendizagem, com rodas de conversa sobre a vida no campo, plantio de hortas, contação de histórias, dentre outras. Além destes aspectos, há o cuidado com a manutenção da escola - pintura, limpeza e organização - atuando também como agentes de mobilização de recursos humanos e financeiros para a aquisição de materiais.

Salienta-se ainda como decisiva a identificação dos professores com as escolas, manifesta nas práticas pedagógicas que buscam reinventar suas atividades para atender a diversidade de uma classe multisseriada. Associa-se a este fator a presença da comunidade como mobilização constante para que as escolas permaneçam desenvolvendo suas atividades de ensinar e aprender.

Em razão da restrita produção científica existente, sugere-se que futuras pesquisas invistam no estudo da modalidade multisseriada, na perspectiva da aprendizagem. A investigação a partir de outros pontos de vista - da equipe gestora municipal, da comunidade, dos alunos - também pode trazer novos conhecimentos acerca do contexto analisado. Estudos comparativos em nível nacional e internacional também podem oferecer contribuições para a educação nas escolas multisseriadas.

\section{Referências}

ALENTEJANO, Paulo; CORDEIRO, Tassia. 80 mil escolas do campo foram fechadas em 21 anos. Brasil de Fato, 29 nov. 2019. Disponível em :

https://www.brasildefato.com.br/2019/11/29/artigo-or-80-mil-escolas-no-campobrasileiro-foram-fechadas-em-21-anos

ARROYO, Miguel Gonzalez; FERNANDES, Bernardo Mançano. A educação básica e o movimento social do campo. Brasília, DF: Articulação Nacional Por Uma Educação Básica do Campo, 1999. Coleção Por Uma Educação Básica do Campo, nº 2. Cap.1. A educação básica e o movimento social do campo. p. 12 a 42. Disponível em: http://portal.mec.gov.br/secad/arquivos/pdf/educacaodocampo/edbasicapopular.pdf.

AZEVEDO, Marcio Adriano; QUEIROZ, Maria Aparecida. Políticas de educação (a partir dos anos 1990) e trabalho docente em escolas multisseriada: experiência em um município do Rio Grande do Norte. In: ANTUNES- ROCHA, Maria Isabe,; HAGE, Salomão Mufarrej(orgs).Escola de direito: reinventando a escola multisseriada. Belo Horizonte: Autêntica Editora, 2010. 
BRASIL. Lei de 15 de outubro de 1927. Manda crear escolasde primeiras letras em todas as cidades, villas e logares mais populosos do Imperio. Disponível em: https://www2.camara.leg.br/legin/fed/lei_sn/1824-1899/lei-38398-15-outubro-1827566692-publicacaooriginal-90222-pl.html

CARDOSO, Maria Angélica; JACOMELI, Mara Regina Martins. Considerações sobre as escolas multisseriadas: Estado da arte. Educere et Educare, v. 5, n. 9, 2010. Disponível em: http://erevista.unioeste.br/index.php/educereeteducare/article/viewFile/3878/3803.

DRUZIAN, Franciele; MEURER, Ana Karine. Escola do campo multisseriada: experiência docente. Revista Geografia Ensino \& Pesquisa, vol. 17, n. 2. 2013. Disponível em: https://periodicos.ufsm.br/geografia/article/view/10777/0.

DUARTE, Claudia Glavam; TASCHETTO, Leonidas Roberto. A escola multisseriada como potência para tensionar algumas "verdades" do campo educacional. In: D’AGOSTINI, Adriana (org). Experiências e reflexões sobre escolas/classes multisseriadas. Florianópolis: Editora Insular, 2014.

FARIA FILHO, Luciano Mendes de; VIDAL, Diana Gonçalves. Os tempos e os espaços escolares no processo de institucionalização da escola primária no Brasil. Rev. Bras. Educ., Rio de Janeiro, n. 14, p. 19-34, 2000. Disponível em: https://www.scielo.br/pdf/rbedu/n14/n14a03.pdf

FREITAS, Helana Célia de Abreu. Rumos da Educação do Campo. Em Aberto, Brasília, v. 24, n. 85, p. 35-49, abr. 2011. Disponível em: http://portal.inep.gov.br/documents/186968/485895/Educa\%C3\%A7\%C3\%A3o+do+Ca mpo/a2fa9177-5611-429d-a62f-ae0a6fcb3502?version=1.1

FREITAS, Maria Natalina Mendes. Heterogeneidade: fios e desafios da escola multisseriada da Ilha de Urubuoca. In: ANTUNES- ROCHA, Maria Isabe,; HAGE, Salomão Mufarrej(orgs). Escola de direito: reinventando a escola multisseriada. Belo Horizonte: Autêntica Editora, 2010.

GIL, Antonio Carlos. Métodos e técnicas de pesquisa social. 6 ed. São Paulo. Atlas, 2012.

HAGE, Salomão Antônio Mufarrej. Transgressão do Paradigma da (multi) Seriação como referência para a construção da Escola Pública do Campo. Educ. Soc., Campinas, v. 35, n. 129, p. 1165-1182, 2014. Disponível em: https://www.scielo.br/pdf/es/v35n129/0101-7330-es-35-129-01165.pdf .

HAGE, Salomão Mufarrej. Classes Multisseriadas: Desafios da educação rural no Estado do Pará/Região Amazônica. In: HAGE, Salomão Mufarrej (org). Educação do campo na Amazônia: retratos de realidade das escolas multisseriadas no Pará. Belém: Grafica e Editora Gutemberg Ltda, 2005.

HERMANN, Nadja. Hermenêutica e Educação. Rio de Janeiro. DP\&A, 2002. 
INSTITUTO NACIONAL DE ESTUDOS E PESQUISAS ANÍSIO TEIXEIRA -

INEP. Panorama da educação no campo. Brasília: Instituto Nacional de Pesquisas Educacionais Anísio Teixeira, 2007. Disponível em: http://portal.inep.gov.br/documents/186968/484154/Panorama+da+Educa\%C3\%A7\%C 3\%A3o+do+Campo/5b9c2ed7-208b-48ff-a803-cd3851c5c6c9?version=1.2

INSTITUTO NACIONAL DE ESTUDOS E PESQUISAS EDUCACIONAIS ANÍSIO TEIXEIRA. Resumo Técnico: Censo da Educação Básica 2018. Brasília: Instituto Nacional de Estudos e Pesquisas Educacionais Anísio Teixeira, 2019. Disponível em: http://download.inep.gov.br/educacao_basica/censo_escolar/resumos_tecnicos/resumo_t ecnico_censo_educacao_basica_2018.pdf

JANATA, Natacha Eugênia; ANHAIA, Edson Marcos de. Escolas/Classes Multisseriadas do Campo: reflexões para a formação docente. Educ. Real.Porto Alegre, v.40, n.3, p.685-704, 2015. Disponível em:

https://www.scielo.br/pdf/edreal/2015nahead/2175-6236-edreal-45783.pdf.

JANATA, Natacha Eugênia; ANHAIA, Edson Marcos de. Projeto Político Pedagógico, possibilidade de repensar as classes multisseriadas?.In: D’AGOSTINI, Adriana (org).

Experiências e reflexões sobre escolas/classes multisseriadas. Florianópolis: Editora Insular, 2014.

MARCONI. Marina de Andrade; LAKATOS, Eva Maria. Fundamentos de metodologia científica - 5. ed. - São Paulo: Atlas 2009.

MARTINS, Suzana Maria Silva. A gestão das classes multisseriadas na educação do campo no município de Inhambupe (BA). 2015. 141f. (mestrado Profissional em Gestão e Avaliação da Educação Pública) - Faculdade de Educação, Universidade Federal de Juiz de Fora, Juiz de Fora, 2015.

MOLINA, Mônica Castagna; FREITAS, Helana Célia de Abreu. Avanços e Desafios na Construção da Educação do Campo. Em Aberto, Brasília, v. 24, n. 85, p. 17-31, 2011. Disponível em:

http://portal.inep.gov.br/documents/186968/485895/Educa\%C3\%A7\%C3\%A3o+do+Ca mpo/a2fa9177-5611-429d-a62f-ae0a6fcb3502?version=1.1

MORAES, Edel et al. Transgredindo o paradigma (multis) seriado nas escolas do campo. In: ANTUNES- ROCHA, Maria Isabel; HAGE, Salomão Mufarrej(orgs).Escola de direito: reinventando a escola multisseriada. Belo Horizonte: Autêntica Editora, 2010 .

PARENTE, Cláudia da Mota Darós. Escolas Multisseriadas: a experiência internacional e reflexões para o caso brasileiro. Ensaio: aval. pol. públ. Educ. Rio de Janeiro, v.22, n.82, p.57-88,Mar. 2014. Disponível em: https://www.scielo.br/pdf/ensaio/v22n82/a04v22n82.pdf.

PEREIRA, Ana Cláudia da Silva. Condições de funcionamento de escolas do campo: em busca de indicadores de custo-aluno-qualidade. In: ANTUNES- ROCHA, Maria 
Isabel; HAGE, Salomão Mufarrej(orgs).Escola de direito: reinventando a escola multisseriada. Belo Horizonte: Autêntica Editora, 2010.

PORTELA, Adélia Luiza; ATTA, Dilza Maria Andrade. A Gestão da Educação Escolar Hoje: O Desafio do Pedagógico: In LUZ, Ana Maria de Carvalho (org). Gestão educacional e qualidade social da educação. Salvador: ISP/ UFBA, 2007.

ROHDEN, Luiz. Interfaces da hermenêutica. Caxias do Sul, RS:EDUCS, 2008.

SANTOS, Fábio Josué Souza dos; MOURA, Terciana Vidal. Políticas Educacionais, modernização pedagógica e racionalização do trabalho docente: problematizando as representações negativas sobre as classes multisseriadas. In: ANTUNES- ROCHA, Maria Isabel; HAGE, Salomão Mufarrej(orgs). Escola de direito: reinventando a escola multisseriada. Belo Horizonte: Autêntica Editora, 2010.

SANTOS, Ana Maria Marcon; ALBUQUERQUE, Eliane Maria Muniz Ramos. A formação continuada e a prática docente no Programa Escola Ativa de São José do Cerrito. In: D’AGOSTINI, Adriana (org). Experiências e reflexões sobre escolas/classes multisseriadas. Florianópolis: Editora Insular, 2014.

SILVEIRA, Josiane Soares. A experiência docente na Escola do Campo Multisseriada Salomão Silveira - Garopaba - Canto de Penha. In: D’AGOSTINI, Adriana (org). Experiências e reflexões sobre escolas/classes multisseriadas. Florianópolis: Editora Insular, 2014.

STEIN, Ernildo. Aproximações sobre Hermenêutica. $2^{\text {a }}$ ed. Porto Alegre. EDIPUCRS, 2004.

TAFAREL, Celi Zulke; MOLINA, Mônica Castagna. As políticas Educacional e Educação do Campo. In: CALDART, Roseli Salete; PEREIRA, Isabel, Brasil; ALENTEJANO, Paulo; FRIGOTTO, Gaudêncio (orgs). Dicionário da Educação do Campo. Rio de Janeiro, São Paulo: Escola Politécnica de Saúde Joaquim Venâncio, Expressão Popular, 2012.

TERUYA, Teresa Kazuko et al. Classes multisseriadas no Acre. Rev. Bras. Estud. Pedagog. Brasília, v.94, n.237, p.564-584, 2013. Disponível em: https://www.scielo.br/pdf/rbeped/v94n237/a11v94n237.pdf

VENDRAMINI, Célia Regina. Qual o futuro das escolas no campo?. Educ. rev. Belo Horizonte, v.31, n.3, p.49-69, 2015. Disponível em: https://www.scielo.br/pdf/edur/v31n3/1982-6621-edur-31-03-00049.pdf

Recebido em 10/10/2019. Aceito para publicação em 20/07/2020. 